\title{
Identification of Stable Resistance to Smut in Pearl Millet
}

\author{
R. P. THAKUR, K. V. SUBBA RAO, and R. J. WILLIAMS, Pearl Millet Improvement Program, International Crops \\ Research Institute for the Semi-Arid Tropics (ICRISAT), Patancheru P.O., Andhra Pradesh, 502 324, India; S. C. \\ GUPTA, ICRISAT-CNRA, Bambey, Senegal; D. P. THAKUR, Haryana Agricultural University, Hisar, 125 004, India; \\ S. D. NAFADE, Millet Research Station, Gujarat Agricultural University, Jamnagar, 361 006, India; N. V. \\ SUNDARAM, ICRISAT, Institute of Agricultural Research, ABU, Zaria, Nigeria; J. A. FROWD, ICRISAT, \\ Ouagadougou, Burkina Faso; and J. E. GUTHRIE, ICRISAT Sahelian Center, Niamey, Niger
}

\begin{abstract}
Thakur, R. P., Subba Rao, K. V., Williams, R. J., Gupta, S. C., Thakur, D. P., Nafade, S. D., Sundaram, N. V., Frowd, J. A., and Guthrie, J. E. 1986. Identification of stable resistance to smut in pearl millet. Plant Disease 70:38-41.

More than 1,500 accessions from a germ plasm working collection and 6,200 advanced breeding lines were screened to identify resistance to smut in pearl millet. All advanced breeding lines were susceptible, but resistance was detected in several germ plasm accessions originating from Nigeria, Senegal, Mali, Cameroon, Uganda, Lebanon, and India. To combine resistance with agronomic eliteness, crosses were made between smut-resistant lines and agronomically elite inbred lines, and pedigree selection was carried out in the segregating generations up to the $F_{6}$ generation under high disease pressure. Stability of resistance was tested through a multilocational testing program, the International Pearl Millet Smut Nursery (IPMSN). Selections from six germ plasm accessions (SSC FS 252-S-4, ICI 7517-S-1, ExB 132-2-S-5-2-DM-1, ExB 46-1-2-S-2, ExB 112-1-S-1-1, and P-489-S-3) and four, newly developed, smut-resistant, agronomically elite lines (ICMPS 100-5-1, 900-9-3, 1600-2-4, and 2000-5-2) showed consistently high levels of smut resistance for 1-6 yr at six or seven locations in India and West Africa. These lines had across-location mean smut severities of less than $5 \%$ compared with $35 \%$ or more in the susceptible checks. These lines were also resistant to downy mildew in India.
\end{abstract}

Pearl millet (Pennisetum americanum (L.) Leeke) is a staple cereal for millions of people in the semiarid tropics. The crop suffers from several diseases, and smut, caused by Tolyposporium penicillariae Bref., is important and widespread in India, Pakistan, and several African countries (7). Although smut on pearl millet was reported in the 1930s from different parts of the world, its potential seriousness was realized only in the early 1970 s with the large-scale commercial cultivation of $F_{1}$ hybrids in India and the introduction of exotic breeding lines into Africa. Control of this disease with fungicides has had limited success $(2,3,5,9,15) . T$. penicillariae is a soilborne pathogen, and infection occurs at flowering through the young fresh stigmas from the airborne sporidia produced by germinating teliospores in the soil (1). Therefore, chemical control would technically be very difficult and

Present address of third author: Ciba-Geigy Ltd., R\&D, Phytopathology, CH-4002, Basle, Switzerland; of eighth author: Plant Industry Branch, Saskatchewan Agriculture, Regina, Canada S4S 0B1

Submitted as journal article 471 by the International Crops Research Institute for the Semi-Arid Tropics (ICRISAT).

Accepted for publication 6 June 1985

The publication costs of this article were defrayed in part by page charge payment. This article must therefore be hereby marked "advertisement" in accordance with 18 U.S.C. \$ 1734 solely to indicate this fact.

C 1986 The American Phytopathological Society probably not economical at the peasant farmers' level. Growing resistant varieties is likely to be the most effective control measure for this disease. Earlier work on resistance identification in India indicated that genotypes from Mali, Nigeria, Zimbabwe, Senegal, South Africa, and India had some degree of resistance to this disease $(4,6,8)$. However, no systematic work had been carried out to identify lines with consistently high levels of smut resistance and to use them in resistance breeding. At the International Crops Research Institute for the SemiArid Tropics (ICRISAT), Patancheru, research on smut of pearl millet was begun in 1977 with the major emphasis on the identification of stable sources of resistance. Our understanding of the interaction between pollination and smut infection (11) and of the biology of $T$. penicillariae (10) led to the development of an effective field screening technique for smut resistance (12). With this technique, many accessions from a genetic resource collection and many advanced breeding lines are being screened each year to identify resistance to smut in pearl millet. This paper describes the progress made during the past $7 \mathrm{yr}$ in the identification of stable smut-resistant lines and their use in a resistance-breeding program. Part of this work was reported as an abstract (14).

\section{MATERIALS AND METHODS}

Screening method. A standard smutscreening method involving artificial inoculation of inflorescences at the bootleaf stage, bagging, and sprinkler irrigation to increase relative humidity (12) has been used at Patancheru since 1982. Previously, screening was done at Hisar in northern India, a "hot spot" location for smut, by inoculating the boot with an aqueous suspension of teliospores and sporidia from water-soaked (16 hr) spore balls of $T$. penicillariae obtained from infected earheads of pearl millet, then bagging the boot. Inoculated earheads were scored for percentage of florets producing smut sori, using a set of standard drawings similar to that used for ergot (13). Because there was no provision for sprinkler irrigation or excessive furrow irrigation to provide high humidity for promoting smut development at Hisar, the major screening activities were shifted to Patancheru in 1982.

Identification and development of resistance. The procedure followed to identify and develop stable smut-resistant lines is outlined in Figure 1.

Screening germ plasm accessions. More than 1,500 accessions from a genetic resource collection obtained from the Genetic Resources Unit of ICRISAT were screened at Hisar between 1977 and 1980. In the initial screening, each accession was grown in one row $4 \mathrm{~m}$ long with $25-30$ plants, and 10 plants in each entry were inoculated and covered with parchment-paper selfing bags. After every 20 rows of test entries, one row of a highly smut-susceptible genotype was planted as a check and 10-20 plants were inoculated similar to the test entries. Individual earheads with no smut, or at the most up to $10 \%$ severity, and with good selfed-seed set $(>80 \%)$ were selected. In the next rainy season, headto-row progenies were grown from the selected earheads for advanced screening; 20 plants per entry were screened, and only smutfree plants were selected. The process of growing head-to-row progenies, screening, and selecting smutfree plants was continued for four to six generations until inbred lines with consistently high smut resistance were obtained.

Screening breeding lines. More than 6,200 lines from the All India Coordinated Millets Improvement Project (AICMIP) and ICRISAT millet-breeding projects were screened between 1977 and 1983. 
These included $F_{1}$ hybrids, progenies, synthetics, varieties, male-sterile lines, and inbred lines. More than $80 \%$ of these entries were screened at Hisar during 1977-1980, and the remaining 20\%, at Patancheru between 1981 and 1983.

Development of smut-resistant lines with improved agronomic traits. During the summer of 1977 at Patancheru, individual plant crosses were made between 12 smut-resistant lines $(\leqslant 5 \%$ severity) and seven low-smut-susceptible $(\leqslant 10 \%$ severity), agronomically elite lines to produce $167 \mathrm{~F}_{1}$ progenies. The $F_{2}$ populations obtained by mixing $\mathrm{F}_{2}$ seed from $F_{1}$ plants were screened (minimum of 100 plants per $F_{2}$ population) at Hisar during the 1979 rainy season, and smutresistant plants ( $\leqslant 5 \%$ severity) with good seed set and desirable plant characters (height 130-150 cm, two or three productive tillers per plant, good head exsertion, head length $>20 \mathrm{~cm}$, good selfed-seed set [>80\%], and time to maturity 90-120 days) were selected. The process of screening and pedigree selection continued up to the $\mathrm{F}_{6}$ generation. $F_{2}$ to $F_{4}$ progeny screening and selection were done at Hisar, and $F_{5}$ to $F_{6}$, at Patancheru with the improved screening technique (12).

Smut-resistant $F_{5}$ lines were also screened for downy mildew resistance during the summer of 1982 in the Patancheru downy mildew nursery, which is operated using an infector-row system (16). Twenty $F_{5}$ lines that were free of downy mildew and had desirable agronomic traits were sib-mated (bulk pollen from 10-20 plants was used to pollinate sister plants in the same population) to produce line bulks and were assigned ICRISAT Millet Pathology Smut (ICMPS) numbers.

Evaluation of stability of resistance. Stability of resistance was evaluated in a coordinated international testing program, the International Pearl Millet Smut Nursery (IPMSN).

Test locations. The locations selected were mainly those where smut is known to occur naturally at a relatively high pressure every year. Locations were Hisar, Jamnagar, and Patancheru in India; Bambey, Senegal, in West Africa; Kamboinse in Burkina Faso; Sadore in Niger; and Samaru in Nigeria. These locations represent the major pearl millet-growing areas of the world from a latitude of $11^{\circ} 11^{\prime}$ (Samaru) to $29^{\circ} 10^{\prime}$ (Hisar) with mean maximum temperatures ranging from 29 to $38 \mathrm{C}$ during the flowering and disease-development periods.

Test entries. Each year an IPMSN set included 29-37 test entries and three check entries-a common susceptible check and a local resistant and a local susceptible entry. The last two were included by the cooperators at their respective locations. During 1978-1981, all test entries were those selected from the genetic resource accessions and breeding lines. The ICMPS lines were included only from 1982. Seed for individual entries for each year were drawn from the same seed lot to eliminate possible variation in smut reaction resulting from different seed stocks.

Nursery management. The nursery was coordinated by pathologists at the ICRISAT Center. Planting was done at the beginning of the rainy season, which normally begins in late June to mid-July at most of the locations. Each entry was planted in a plot of two rows $4 \mathrm{~m}$ long in a randomized block design with two replicates. Interrow $\times$ interplant spacings varied from $75 \times 20$ to $50 \times 10 \mathrm{~cm}$ at

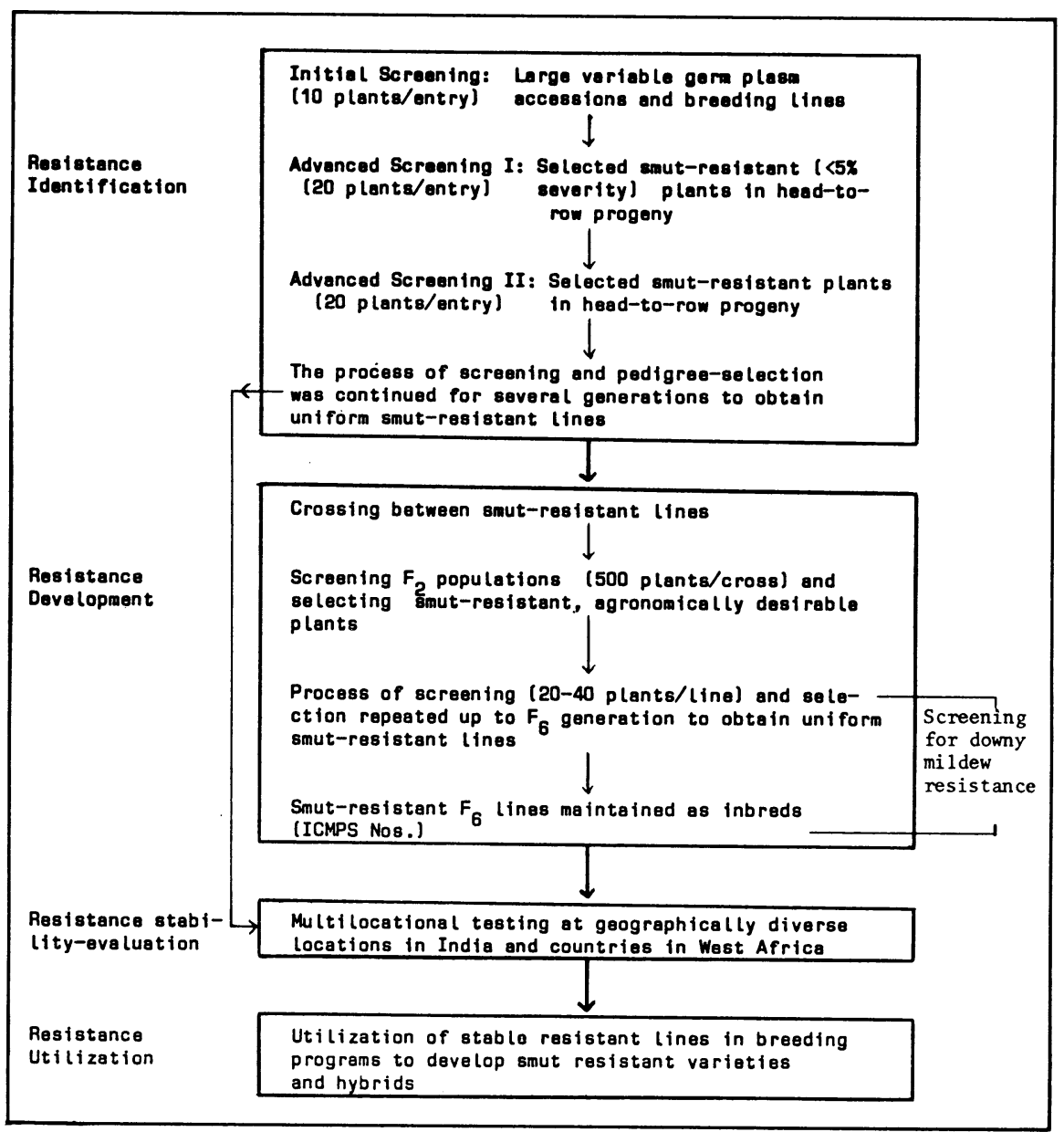

Fig. 1. Scheme for identification and development of stable resistance to smut in pearl millet.

Table 1. Summary of screening pearl millet germ plasm lines for smut resistance at Patancheru and Hisar during 1976-1983

\begin{tabular}{|c|c|c|c|c|}
\hline \multirow{2}{*}{$\begin{array}{l}\text { Country of } \\
\text { origin }\end{array}$} & \multirow{2}{*}{$\begin{array}{c}\text { Lines } \\
\text { screened }\end{array}$} & \multicolumn{2}{|c|}{ Lines with smut severity $(\%)^{a}$ of } & \multirow{2}{*}{$\begin{array}{l}\text { Lines }^{b} \\
\text { selected }\end{array}$} \\
\hline & & $\mathbf{0}$ & $\leqslant 10$ & \\
\hline Cameroon & 40 & 11 & 8 & 4 \\
\hline India & 684 & 23 & 118 & 11 \\
\hline Lebanon & 15 & 2 & 4 & 1 \\
\hline Mali & 90 & 29 & 47 & 8 \\
\hline Niger & 390 & 28 & 119 & 2 \\
\hline Nigeria & 216 & 13 & 49 & 2 \\
\hline Senegal & 119 & 27 & 77 & 4 \\
\hline Uganda & 37 & 5 & 7 & 2 \\
\hline USSR & 7 & 0 & 0 & 0 \\
\hline Others & 23 & 23 & 7 & 0 \\
\hline
\end{tabular}

${ }^{\mathrm{a}}$ Based on initial screening of 10 plants per line.

${ }^{\mathrm{b}}$ Lines with high smut resistance $(\leqslant 2 \%$ severity) and good seed set in advanced screening II. different locations. Ten plants were per row. At Patancheru, (noon and evening) on rainfree days to maintain high relative humidity during the period from inoculation to disease rating. At other locations, sprinkler irrigation was not provided. Smut severity scores (percentage of florets producing smut sori) were taken 20-25 days after inoculation. The entries were also screened for downy mildew resistance and ergot resistance at the Patancheru multiple-disease nursery. Data on downy mildew scores were also obtained from provided sprinkler irrigation was 
the other locations in India. Data received from cooperators were analyzed to determine the mean and range of smut severity and downy mildew incidence for each entry at and across locations. A detailed report was prepared for each year's IPMSN, and copies were made available to cooperators and other interested scientists

\section{RESULTS}

Resistance in germ plasm accessions and breeding lines. Of more than 1,500 germ plasm accessions screened, smut resistance was detected only in 34 accessions, which originated from Cameroon, India, Lebanon, Mali, Niger, Nigeria, Senegal, and Uganda (Table 1). Repeated screening and pedigree selection provided lines with uniformly high levels of smut resistance. A large proportion of breeding lines (65-95\%) from AICMIP and ICRISAT were found susceptible $(>10 \%$ smut severity), and the remaining lines, which were less susceptible (up to $10 \%$ severity) in the initial screening, showed more than $10 \%$ severity in the subsequent advanced screening. Hybrids and male-sterile lines were generally more susceptible than inbreds and population progenies.

Resistance with improved agronomic traits. In the $\mathrm{F}_{2}$ generation, $75 \%$ of the progenies of crosses between smutresistant lines and agronomically elite lines showed $\leqslant 5 \%$ smut severity, which increased to $>90 \%$ in the $\mathrm{F}_{4}$ to $\mathrm{F}_{6}$ generations. Resistance selection in the progenies ranged from $0.9 \%$ in $\mathrm{F}_{2}$ to $8.9 \%$ in the $F_{5}$ generation under a fairly high smut pressure $(53-93 \%$ severity in the susceptible checks) in the screening nurseries (Table 2). Sixteen smutresistant line-bulks (ICMPS) made in the summer of 1982 from the selected agronomically desirable sister lines showed improved agronomic traits over the parental lines in the 1983 rainy season evaluation. Details on improvement in agronomic traits and grain yield will be reported separately.

Stability of resistance. The reactions to smut of 10 lines that were evaluated multilocationally through IPMSN for 1-6 yr are presented in Table 3. Disease pressure varied considerably at and across locations over years. Among the Indian locations, Patancheru provided the maximum disease pressure (61-91\% severity on the susceptible check)

Table 2. Number of lines screened, crosses represented, and plants inoculated and selected in $F_{2}$ to $F_{6}$ generations in a program to develop high levels of smut resistance with improved agronomic traits in pearl millet

\begin{tabular}{|c|c|c|c|c|c|c|c|c|c|}
\hline \multirow[b]{2}{*}{ Generation } & \multirow[b]{2}{*}{ Year } & \multirow[b]{2}{*}{ Location } & \multirow[b]{2}{*}{$\begin{array}{c}\text { Entries } \\
\text { screened }\end{array}$} & \multirow[b]{2}{*}{$\begin{array}{c}\text { Crosses } \\
\text { represented }\end{array}$} & \multicolumn{2}{|c|}{ Plants inoculated } & \multirow[b]{2}{*}{$\begin{array}{c}\text { Plants } \\
\text { selected }^{\mathrm{a}}\end{array}$} & \multirow[b]{2}{*}{$\begin{array}{c}\text { Selection } \\
(\%)\end{array}$} & \multirow{2}{*}{$\begin{array}{c}\text { Smut }^{\mathbf{b}} \\
\text { severity }(\%) \\
\text { in susceptible } \\
\text { check }\end{array}$} \\
\hline & & & & & $\begin{array}{c}\text { Minimum } \\
\text { per line }\end{array}$ & $\begin{array}{c}\text { Total per } \\
\text { generation }\end{array}$ & & & \\
\hline $\mathrm{F}_{2}$ & 1979 & Hisar & 167 & 167 & 100 & 25,250 & 217 & 0.9 & 57 \\
\hline $\mathrm{F}_{3}$ & 1980 & Hisar & 217 & 40 & 20 & 5,680 & 672 & 11.8 & 70 \\
\hline $\mathrm{F}_{4}$ & 1981 & Hisar & 672 & 36 & 10 & 10,500 & 679 & 6.5 & 53 \\
\hline $\mathrm{F}_{5}$ & 1982 & Patancheru & 679 & 31 & 10 & 8,245 & 740 & 8.9 & 84 \\
\hline$F_{6}$ & 1983 & Patancheru & 740 & 20 & 5 & 4,050 & $\cdots^{\mathrm{c}}$ & $\cdots$ & 93 \\
\hline
\end{tabular}

${ }^{a}$ Up to $10 \%$ smut severity in $F_{2}$ and smutfree plants in $F_{3}$ to $F_{6}$

${ }^{\mathrm{b}}$ Mean of $10-20$ inoculated plants per plot.

${ }^{\mathrm{C}}$ No selection was made because of poor plant growth caused by prolonged rainy season.

Table 3. Summary of the performance of the best smut-resistant lines of pearl millet in the multilocational testing program at Indian and West African locations during 1978-1983

\begin{tabular}{|c|c|c|c|c|c|c|c|c|c|c|c|c|c|c|c|c|c|}
\hline \multirow[b]{3}{*}{ Entry $^{\mathrm{a}}$} & \multicolumn{16}{|c|}{ Smut severity $(\%)^{b}$} & \multirow{3}{*}{$\begin{array}{c}\text { Downy } \\
\text { mildew } \\
\text { incidence } \\
(\%)\end{array}$} \\
\hline & \multicolumn{6}{|c|}{ Hisar (India) } & \multicolumn{6}{|c|}{ Jamnagar (India) } & \multicolumn{4}{|c|}{ Patancheru (India) } & \\
\hline & 1978 & 1979 & 1980 & 1981 & 1982 & 1983 & 1978 & 19791 & 1980198 & 311982 & 1983 & & 1980 & 1981 & 1982 & 1983 & \\
\hline SSC FS 252-2-4 & 0 & 0 & 0 & $-^{d}$ & 0 & 0 & 1 & 1 & 0 & 0 & 0 & & 0 & 0 & 0 & 0 & 2 \\
\hline ICI $7517-\mathrm{S}-1$ & 0 & 0 & 0 & $<1$ & $<1$ & 0 & $<1$ & $<1$ & $<1$ & 0 & 0 & & 0 & 0 & $<1$ & 0 & 1 \\
\hline ExB 132-2-S-5-2-DM-1 & 6 & 2 & $<1$ & 1 & $<1$ & 0 & 2 & 1 & $<1$ & 0 & 0 & & $<1$ & 1 & $<1$ & 0 & 2 \\
\hline ExB 46-1-2-S-2 & - & - & $<1$ & $<1$ & 0 & 0 & - & - & $<1$ & $<1$ & 0 & & 4 & $<1$ & $<1$ & 0 & $<1$ \\
\hline ExB 112-1-S-1-1 & - & - & $<1$ & 0 & $<1$ & 0 & - & - & 0 & 0 & 0 & & 0 & 0 & 0 & 0 & 0 \\
\hline P-489-S-3 & - & - & - & $<1$ & 0 & $<1$ & - & - & - & $<1$ & 0 & & - & 0 & 0 & 0 & $<1$ \\
\hline ICMPS 100-5-1 & - & - & - & - & 0 & 0 & - & - & - & $<1$ & 0 & & - & - & 0 & 0 & 1 \\
\hline ICMPS 900-9-3 & - & - & - & - & 0 & 0 & - & - & - & $<1$ & 0 & & - & - & 0 & 0 & 1 \\
\hline ICMPS 1600-2-4 & - & - & - & - & $<1$ & $<1$ & - & - & - & 0 & 0 & & - & - & 0 & 0 & 3 \\
\hline ICMPS $2000-5-2$ & - & - & - & - & $<1$ & $<1$ & - & - & - & $<1$ & 0 & & - & - & $<1$ & 0 & 1 \\
\hline \multirow[t]{3}{*}{ Susceptible check } & 15 & 25 & 30 & 11 & 36 & 78 & 4 & 11 & 31 & 58 & 44 & & 61 & 91 & 72 & 82 & 52 \\
\hline & \multicolumn{6}{|c|}{ Bambey (Senegal) } & \multicolumn{4}{|c|}{ Samaru (Nigeria) } & \multicolumn{5}{|c|}{ Kamboinse (Burkina Faso) } & \multicolumn{2}{|c|}{ Sadore (Niger) } \\
\hline & 1978 & 1979 & 1980 & 1981 & 1982 & 1983 & 1978 & 1980 & 1981 & 1983 & & 1978 & 197 & 79 & 1982 & 1981 & 1983 \\
\hline SSC FS 252-2-4 & $<1$ & $<1$ & 0 & - & 1 & 2 & 12 & 4 & 4 & 19 & & 0 & 0 & 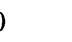 & $<1$ & 0 & $<1$ \\
\hline ICI $7517-S-1$ & 1 & 0 & 1 & 0 & $<1$ & 1 & 13 & 10 & 3 & 2 & & 0 & 0 & 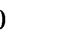 & $<1$ & 4 & $<1$ \\
\hline ExB 132-2-S-5-2-DM-1 & 24 & 7 & $<1$ & 2 & $<1$ & 1 & 32 & 15 & 6 & 12 & & $<1$ & 1 & 1 & $<1$ & 1 & $<1$ \\
\hline ExB 46-1-2-S-2 & - & - & 1 & $<1$ & $<1$ & 1 & - & 21 & 4 & 6 & & - & - & - & $<1$ & $<1$ & 0 \\
\hline ExB 112-1-S-1-1 & - & - & $<1$ & $<1$ & 3 & 1 & - & 14 & 4 & 1 & & - & - & & $<1$ & $<1$ & $<1$ \\
\hline P-489-S-3 & - & - & - & 9 & 2 & 2 & - & - & 1 & 1 & & - & - & - & $<1$ & $<1$ & $<1$ \\
\hline ICMPS $100-5-1$ & - & - & - & - & $<1$ & 1 & - & - & - & 3 & & - & - & - & - & - & $<1$ \\
\hline ICMPS 900-9-3 & - & - & - & - & $<1$ & 1 & - & - & - & 5 & & - & - & & - & - & 0 \\
\hline ICMPS $1600-2-4$ & - & - & - & - & 2 & 1 & - & - & - & 8 & & - & - & & - & - & $<1$ \\
\hline ICMPS 2000-5-2 & - & - & - & - & $<1$ & 1 & - & - & - & 7 & & - & - & & - & - & 6 \\
\hline Susceptible check & 17 & 11 & 31 & 84 & 24 & 54 & 65 & 68 & 51 & 32 & & - & 67 & & 43 & 28 & 47 \\
\hline
\end{tabular}

${ }^{a}$ Origin of entries: $\mathrm{SSC}=$ superserere composite from Uganda, ICI = ICRISAT inbred, EB = Ex-Bornu $(\mathrm{Nigeria}), \mathrm{P}=\mathrm{Senegal}$, and ICMPS $=$ ICRISAT Millet Pathology Smut lines.

${ }^{b}$ Mean severity based on 20-40 inoculated/bagged inflorescences in two replicates.

'Mean based on 1983 evaluation at three Indian locations: Hisar, Jamnagar, and Patancheru.

$\mathrm{d}_{-}=$Entries not tested. 
followed by Hisar and Jamnagar, and in West Africa, Samaru provided the maximum pressure $(32-68 \%$ severity on the susceptible check) followed by Kamboinse, Bambey, and Sadore. All 10 lines showed consistently high levels of smut resistance $(0-6 \%$ severity) across three Indian locations during 2-6 yr of testing. At the West African locations (except Samaru), these lines maintained high levels of resistance (0-9\% severity) during 1-6 yr of testing, except ExB 1322-S-5-2-DM-1, which showed $24 \%$ severity at Bambey in 1978. At Samaru, although smut severities of the lines were always lower than that of the susceptible check, severities varied from year to year even for the same line. All smut-resistant lines were also resistant to downy mildew at the Indian locations (Table 3 ) but were susceptible to ergot. The ICMPS lines generally showed better agronomic traits than the other lines.

\section{DISCUSSION}

Identification of diverse and stable sources of resistance to a disease is a prerequisite to a resistance-breeding program. Because smut of pearl millet is a widespread problem, resistance identified should be stable across environments over years. Some of the lines selected and developed at Patancheru have shown stable smut reactions across locations in India and West Africa for 1-6 yr. Smut pressure has been variable at and across locations over years depending upon the prevailing weather conditions during the period from inoculation to disease development.

Among the weather factors, relative humidity is the most important for disease development (12). Lack of sprinkler irrigation facilities, except at the Patancheru location, has probably contributed largely to the variation in smut pressure, and this clearly indicates the need to provide high humidity, as with resistance screening for downy mildew (16) and ergot (13) in pearl millet. Despite this quantitative variation in disease pressure, however, the resistant entries have generally shown consistently high levels of resistance across locations over years, clearly showing the stability of resistance in these lines. At present, these lines are the only known resistance sources for use in the resistance-breeding programs in India, Niger, Senegal, and
Burkina Faso and to a certain extent in Nigeria.

Although smuts generally are known to be highly variable, there are no definite indications from our multilocational testing data of any pathogenic variations in $T$. penicillariae populations. At Samaru, for example, some lines have shown differential severities but no one line has shown consistently similar reactions over years. It is, however, desirable to have a more precise test of genotypes in more environments, particularly in Africa, to detect the pathogenic variations.

Smut resistance has been detected in germ plasm lines originating from seven geographically diverse countries of Asia and Africa, and presumably, these will also have genetic diversity for resistance. We are continuing to screen more of the pearl millet genetic resource collections, which currently consist of about 16,000 accessions from 30 countries, to find more new diverse sources of smut resistance.

Because pearl millet is a highly crosspollinated crop, smut-resistant inbreds developed through pedigree selection showed poor agronomic traits resulting from inbreeding depression. Such lines, though valuable resistant sources, have limited direct use in a population breeding program. Our attempt to produce smut-resistant, agronomically desirable lines from crosses between smut-resistant inbreds has been successful, and several of these (ICMPS lines) have shown stable resistance in multilocational testing. Because the smut-resistant lines have also shown resistance to downy mildew in India, these lines will be useful in a population-improvement program to develop smut- and downy mildewresistant varieties.

At the ICRISAT Center, Patancheru, smut resistance is being used directly in the population-improvement projects to breed smut-resistant varieties by transferring resistance into hybrid seed parents and pollinator parents using backcross breeding to develop smut-resistant hybrids. We will make available on request to any scientist information on lines and small quantities of seed of smutresistant lines described in this paper.

\section{ACKNOWLEDGMENTS}

We wish to thank N. A. Thakar and H. R. Dave,
Jamnagar, India; P. Sereme, Kamboinse, Burkina Faso; and all other pathologists who helped in conducting the nursery; B. S. Talukdar, pearl millet breeder, ICRISAT, for making some of the crosses; S. D. Singh, pearl millet pathologist, ICRISAT, for his help in screening for downy mildew resistance at Patancheru; and S. B. King, principal pathologist, Pearl Millet Improvement Program, ICRISAT, for his useful suggestions on the manuscript.

\section{LITERATURE CITED}

1. Bhatt, R.S. 1946. Studies in Ustilaginales. 1. The mode of infection of the bajra plant (Pennisetum typhoides Stapf \& Hubbard) by the smut, Tolyposporium penicillariae Bref. J. Indian Bot. Soc. 25:163-186.

2. Bhowmik, T. P., and Sundaram, N. V. 1971. Control of pearl millet smut with systemic fungicides. Plant Dis. Rep. 55:87-88.

3. Mathur, B. L., Singh, G., and Gupta, R. B. L. 1971. Effect of fungicides on smut ( Tolyposporium penicillariae) and seed mycoflora of pearl millet. Hind. Antibiot. Bull. 14:14-16.

4. Murthy, B. R., Upadhyay, M. K., and Manchanda, P. L. 1967. Classification and cataloguing of a world collection of genetic stocks of Pennisetum (catalogue of world collection of sorghum and Pennisetum). Indian J. Genet. Plant Breed. 27(1):313-394.

5. Pathak, V. N., and Gaur, S. C. 1975. Chemical control of pearl millet smut. Plant Dis. Rep. 59:537-538

6. Pathak, V. N., and Sharma, R. K. 1976. Method of inoculation of Pennisetum typhoides with Tolyposporium penicillariae and evaluation of germ plasm for smut resistance. Indian J. Mycol. Plant Pathol. 6:102.

7. Rachie, K. O., and Majmudar, J. V. 1980. Pear Millet. Pennsylvania State University Press, University Park. 307 pp.

8. Sangwan, M. S., and Thakur, D. P. 1981 Screening of pearl millet genotypes for smut disease. Haryana Agric. Univ. J. Res. 11:249-252.

9. Sharma, K. B., and Sharma, L. C. 1976. Chemical control of pearl millet rust and smut. PANS 22:410-411.

10. Subba Rao, K. V., and Thakur, R. P. 1983. Tolyposporium penicillariae, the causal agent of pearl millet smut. Trans. Br. Mycol. Soc. 81:597-603.

11. Thakur, R. P., Subba Rao, K. V., and Williams R. J. 1983. Effects of pollination on smut development in pearl millet. Plant Pathol. 32:141-144.

12. Thakur, R. P., Subba Rao, K. V., and Williams, R. J. 1983. Evaluation of a new field screening technique for smut resistance in pearl millet. Phytopathology 73:1255-1258.

13. Thakur, R. P., and Williams, R. J. 1980 Pollination effects on pearl millet ergot. Phytopathology 70:80-84

14. Thakur, R. P., Williams, R. J., and Subba Rao, K. V. 1983. Identification of stable resistance to smut in pearl millet. (Abstr.) Int. Congr. Plant Pathol., 4th. Melbourne, Australia.

15. Wells, H. D. 1967. Effectiveness of two 1,4oxathiin derivatives for control of Tolyposporium smut of pearl millet. Plant Dis. Rep. 51:468-469.

16. Williams, R. J., Singh, S. D., and Pawar, M. N. 1981. An improved field screening technique for downy mildew resistance in pearl millet. Plant Dis. 65:239-241. 